\title{
NEUTROPHIL-TO-LYMPHOCYTE RATIO AS A MARKER OF ACUTE EXACERBATION AND DISEASE SEVERITY IN CHRONIC OBSTRUCTIVE PULMONARY DISEASE
}

\author{
Usha Sekkizhar1, Anoop Paulose², Thiriveni Balaji G. S3, Jegatheesh Ramaraj4
}

1 Professor, Department of Medicine, Coimbatore Medical College, Coimbatore, Tamilnadu, India.

2Junior Resident, Department of Medicine, Coimbatore Medical College, Coimbatore, Tamilnadu, India.

${ }^{3}$ Associate Professor, Department of Pathology, Coimbatore Medical College, Coimbatore, Tamilnadu, India.

4Junior Resident, Department of Medicine, Coimbatore Medical College, Coimbatore, Tamilnadu, India.

\section{ABSTRACT}

\section{BACKGROUND}

Chronic Obstructive Pulmonary Disease (COPD) is a preventable and treatable disease, which consists of constant expiratory limitation of the flow of air which is not fully reversible. Neutrophil-to-Lymphocyte Ratio (NLR) is an effortless and basic parameter that is readily obtained from the simplest and easily obtainable complete blood count, even in peripheral hospitals.

\section{MATERIALS AND METHODS}

In our cross-sectional study a total of 100 patients with COPD, attending Coimbatore Medical College Hospital OPD was included based on the inclusion and exclusion criteria over a period of one year. All the data were entered in a data collection sheet in an Excel format and analysed using SPSS Software. Numerical values were reported using mean and standard deviation or median. Categorical values are reported using number and percentages. Using Unpaired T-test and ANOVA as Statistical Methods, Probability (p) value less than 0.05 was considered as statistically significant.

\section{RESULTS}

In our study we have found that age, duration of illness and the BODE index was correlated with NLR. It was also found in our study that NLR is inversely related to FEV1 and GOLD grades. The neutrophil-lymphocyte ratio was more in patients with more severity of disease shown by MMRC grading and it indicates that higher the NLR ratio more severe the disea se will be on dyspnoea score. It is also raised in smoker with acute exacerbation of COPD patients. NLR was independently correlated with all parameters of BODE index with p value of 0.001 . Correlation of chest x-ray and CT chest with mean NLR level for emphysema plus chronic bronchitis was 4.8 and showed statistical significance with $p$ value of 0.001 .

\section{CONCLUSION}

As an inexpensive, accessible and convenient assay, complete haemogram may be used as a practical means in the prediction of prognosis of patients with COPD in future clinical settings. Several types of inflammatory cells and mediators have been found to be involved in the progression of COPD. Our study evaluated the association of NLR with acute exacerbations and disease severity in COPD.

\section{KEY WORDS}

COPD, Exacerbation, Mortality, Neutrophil-Lymphocyte Ratio, Prognosis.

HOW TO CITE THIS ARTICLE: Sekkizhar U, Paulose A, Balaji TGS, et al. Neutrophil-to-lymphocyte ratio as a marker of acute exacerbation and disease severity in chronic obstructive pulmonary disease. J. Evolution Med. Dent. Sci. 2018;7(43):4651-4658, DOI: $10.14260 /$ jemds/2018/1038

\section{BACKGROUND}

Chronic obstructive pulmonary disease is regarded as the most important public health problem that affect our part of the world. It is the fourth leading cause of mortality in the world, and by 2020 will become the next cause next to ischaemic heart disease and stroke as per WHO.[1] COPD mostly affecting males who are mainly smokers and characterised by limitation of airflow which is not fully transformable to normal along with increased long-term inflammatory response in airways of the tracts of lungs, being viral and bacterial pathogens as the prime cause of exacerbations.[2]

'Financial or Other Competing Interest': None.

Submission 11-09-2018, Peer Review 05-10-2018,

Acceptance 11-10-2018, Published 22-10-2018.

Corresponding Author:

Usha Sekkizhar,

\#47 SKV Nagar, Kalveeran Palayam,

Bharathiyar University Post,

Coimbatore-641046, Tamilnadu, India.

E-mail: ushamedicine@gmail.com

DOI: $10.14260 / \mathrm{jemds} / 2018 / 1038$
Macrophage and cells lining the mucous membrane activation, which produce proteinases and chemokines, which attract other inflammatory and immune cells, interleukin-8 (IL-8) and TNF alpha are released in turn cause attraction of neutrophils to the site are the main reasons of inflammation that is occurring in COPD.

Neutrophil-to-Lymphocyte Ratio (NLR) is an effortless and basic parameter that is readily obtained from the simplest and easily obtainable complete blood count, even in peripheral hospitals. Inflammation is regarded as a set of interactions between and among immune related cells such as lymphocytes, neutrophils which in turn lead to killing of tissues and destruction which is going on in COPD. One of the inflammatory markers in COPD is NLR and also has its relationship between many diseases like cardiovascular disease, kidney disease etc. ${ }^{[3-5]}$

In this study, the association that occurs between acute exacerbation of COPD and NLR is found out which help to assess the morbidity and mortality of condition without the help of costly investigation, as NLR is easily obtainable investigation and low cost one. 
COPD is reported to have an estimated disease burden of 210 million people worldwide.[6] Globally, COPD was the fourth leading cause of death (5.1\%) in 2004 and is projected to occupy the third position (8.6\%) in 2030.[7]

According to the World Health Organisation report, the prevalence of COPD ranges between $4 \%$ and $20 \%$ in the Indian adults.[6] According to a recent systematic review, $[8]$ which includes estimates from the INSEARCH and other major studies in India, the prevalence of CB seems to range between $6.5 \%$ and $7.7 \%$ in rural and upto $9.9 \%$ in urban India.

India has the highest percentage of COPD mortality, which is more than 64.7 estimated age standardised death rate per 100,000 amongst both sexes. This predicts that around 556,000 deaths occurring in case of India (> 20\%) out of the world total of 2,748,000 annually.[9] The reported prevalence estimates have ranged from 2 to $22 \%$ in men and from 1.2 to $19 \%$ in women.[10] The recent 'Indian Study of Asthma, Respiratory Symptoms and Chronic Bronchitis' (INSEARCH) study of 85,105 men and 84,470 women from 12 urban and 11 rural sites reported the prevalence of chronic bronchitis to be $3.49 \%$ ( $4.29 \%$ in males and $2.7 \%$ in females) in adults $>35$ years.[11]

\section{Aims and Objectives}

- $\quad$ To identify the possible correlation between neutrophilto-lymphocyte ratio and severity of COPD.

- To identify correlation between NLR with pulmonary function test (FEV1) in COPD patients.

- To study the prospects of NLR considered to be newer, cheaper indicator in acute episodes of COPD.

\section{MATERIALS AND METHODS}

\section{Study Design}

The study was cross-sectional study.

\section{Study Period}

The study was carried out in the Department of Medicine at Coimbatore Medical College and Hospital from July 2016 to June 2017.

\section{Study Population}

After obtaining written, understandable, informed signed consent, detailed history and examination were done in 100 patients of OPD were included in the study.

\section{Inclusion Criteria}

Stable diagnosed COPD patients of age 40 years or older who were current or ex-smokers, based on clinical history and examination, attending Coimbatore Medical College Hospital Outpatient Department.

\section{Exclusion Criteria}

1. Patients with Bronchial Asthma, Bronchiectasis or Bullous lung disorders.

2. Patients with active pulmonary tuberculosis.

3. Patients with other inflammatory diseases such as malignancy, arthritis.

4. Inflammatory bowel diseases or connective tissue disorders.

5. Patients with hepatic disease, renal disease, cardiac disease.
6. Patients with any other acute or chronic respiratory infections.

7. Patients with Diabetes Mellitus.

8. Patients receiving long-term antibiotics.

9. Patients who are on systemic corticosteroids, immunosuppressive therapy.

10. Pregnant or breastfeeding women.

\section{Statistical Analysis}

All the data were entered in a data collection sheet in an Excel format and analysed using SPSS Software. Numerical values were reported using mean and standard deviation or median. Categorical values are reported using number and percentages. The statistical methods used was ANOVA.

\section{RESULTS}

In our clinical study, where neutrophil lymphocyte ratio was obtained from COPD patients and observed for their disease severity. The patients who underwent the study were examined clinically along with detailed history, complete blood count and spirometry.

Our study included 100 patients, of that $10 \%$ had mild, $32 \%$ had moderate, $17 \%$ had severe and $41 \%$ had very severe COPD. All the patients had cough as the major symptom along with wheezing and crepitation were the predominant signs. $46 \%$ of patients had fever and absent in $54 \%$ and those who had fever had more severe form of exacerbation.

\begin{tabular}{|c|c|c|}
\hline Age in Years & No. of Patients & Percentage \\
\hline$<50$ & 9 & $9 \%$ \\
\hline $51-60$ & 31 & $31 \%$ \\
\hline $61-70$ & 48 & $48 \%$ \\
\hline$>70$ & 12 & $12 \%$ \\
\hline \multicolumn{3}{|c|}{ Table 1. Age Distribution } \\
\hline
\end{tabular}

Major group (48\%) under the study was of age group 6170 years, which shows the average age group of the disease in our study. Rural population comprised of $61 \%$ showing major predisposition of COPD to rural areas in our study, and $48 \%$ of patients had duration of illness for more than 10 years. Body mass indices of the patients who participated in this study were almost equally divided in all groups of $<18,18-23$ and $>23$ BMIs. The severity of the disease in case of affecting the daily life was shown by 6-minute walk distance in which $31 \%$ was not able to walk above 149 metres in 6 minutes showing the severity of the condition in those patients.

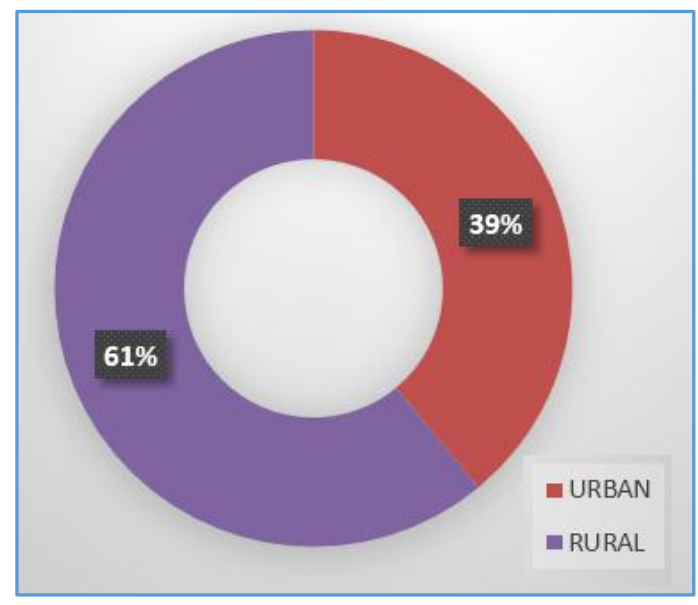

Chart 1. Place of Living 
$91 \%$ of people participated in the study were males and $9 \%$ females, all of the females had biomass fuel exposure, so it is considered as the main aetiology in them. $68 \%$ of patients were smokers, $52 \%$ exposed to biomass fuel and $56 \%$ patients had occupational and environmental exposure.

\begin{tabular}{|c|c|c|c|c|}
\hline Parameters & Exposure & $\begin{array}{l}\text { Neutrophil } \\
\text { Lymphocyte } \\
\text { Ratio Mean } \\
\text { (SD) }\end{array}$ & $P$ value & $\begin{array}{l}\text { Statistical } \\
\text { Method }\end{array}$ \\
\hline \multirow{2}{*}{ Smoking } & Yes & $4.38(1.37)$ & \multirow{2}{*}{0.001} & \multirow{2}{*}{$\begin{array}{c}\text { Unpaired T } \\
\text { Test }\end{array}$} \\
\hline & No & $2.69(1.2$ & & \\
\hline \multirow{2}{*}{ Biomass Fuel } & Yes & $4.25(1.54)$ & \multirow{2}{*}{0.005} & Unpaired T \\
\hline & No & $3.39(1.45)$ & & \\
\hline \multirow{2}{*}{$\begin{array}{c}\text { Environmental } \\
\text { Exposure }\end{array}$} & Yes & $4.12(1.57)$ & \multirow{2}{*}{0.043} & Unpaired T \\
\hline & No & $3.38(1.46)$ & & Test \\
\hline
\end{tabular}

$49 \%$ of patients had grade 3 severity on MMRC scale followed by $26 \%$ of grade $2,13 \%$ of grade 4 and $12 \%$ of grade 1 respectively. $43 \%$ had very severe restriction based on FEV1, while $30 \%$ had moderate, $15 \%$ had severe restriction and $12 \%$ had mild restriction, showing that almost half the patients had very severe restriction based on spirometry.

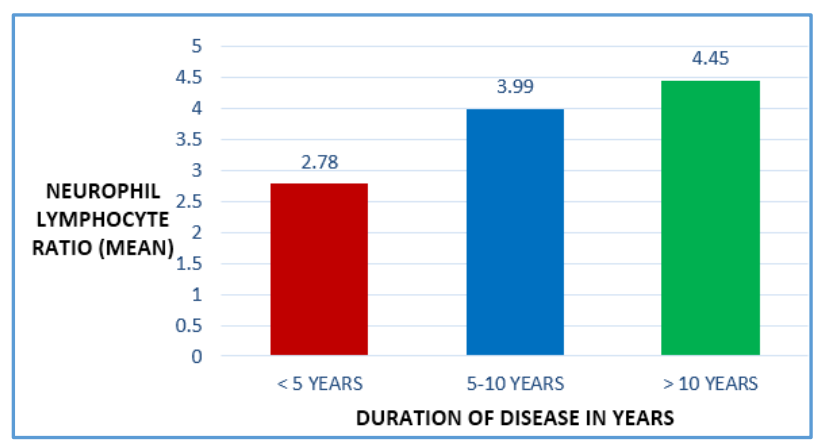

Chart 2. Duration of Years vs. Mean NLR

\begin{tabular}{|c|c|c|c|c|}
\hline Symptoms & Presence & \begin{tabular}{|c|} 
Neutrophil \\
Lymphocyte \\
Ratio Mean \\
(SD)
\end{tabular} & $P$ value & $\begin{array}{c}\text { Statistical } \\
\text { Method }\end{array}$ \\
\hline \multirow{2}{*}{ Fever } & Yes & $4.81(1.19)$ & \multirow{2}{*}{0.001} & \multirow{2}{*}{$\begin{array}{l}\text { Unpaired } \\
\text { T Test }\end{array}$} \\
\hline & No & $3.34(1.48)$ & & \\
\hline \multirow{2}{*}{ Crepitations } & Yes & $4.75(1.15)$ & \multirow{2}{*}{0.001} & \multirow{2}{*}{$\begin{array}{c}\text { Unpaired } \\
\text { T Test }\end{array}$} \\
\hline & No & $2.58(1.09)$ & & \\
\hline \multirow{2}{*}{ Wheezing } & Yes & $4.04(1.54)$ & \multirow{2}{*}{0.001} & \multirow{2}{*}{$\begin{array}{c}\text { Unpaired } \\
\text { T Test }\end{array}$} \\
\hline & No & $2.34(0.34)$ & & \\
\hline \multirow{2}{*}{ Cyanosis } & Yes & $5.07(0.84)$ & \multirow{2}{*}{0.001} & \multirow{2}{*}{$\begin{array}{c}\text { Unpaired } \\
\text { T Test }\end{array}$} \\
\hline & No & $2.83(1.25)$ & & \\
\hline \multirow{2}{*}{ Clubbing } & Yes & $5.13(0.89)$ & \multirow{2}{*}{0.001} & \multirow{2}{*}{$\begin{array}{c}\text { Unpaired } \\
\text { T Test }\end{array}$} \\
\hline & No & $3.43(1.49)$ & & \\
\hline \multirow{2}{*}{$\begin{array}{c}\text { Pedal } \\
\text { Oedema }\end{array}$} & Yes & $4.78(1.19)$ & \multirow{2}{*}{0.001} & \multirow{2}{*}{\begin{tabular}{|c|} 
Unpaired \\
T Test
\end{tabular}} \\
\hline & No & $3.13(1.41)$ & & \\
\hline
\end{tabular}

Neutrophil lymphocyte ratio was correlated with each parameter and their results were as follows: Age and duration of illness was correlated with NLR with $p$ value being 0.748 and 0.001 showing its significance towards duration of illness. Those patients who were smokers had high NLR with average of 4.38 compared to the non-smoker patients showing that NLR is raised in smokers with acute exacerbation COPD patients.

\begin{tabular}{|c|c|c|c|c|}
\hline Grade & Severity & $\begin{array}{l}\text { Neutrophil } \\
\text { Lymphocyte } \\
\text { Ratio Mean } \\
\text { (SD) }\end{array}$ & P value & $\begin{array}{l}\text { Statistical } \\
\text { Method }\end{array}$ \\
\hline \multirow{4}{*}{ MMRC } & Grade 1 & $1.98(0.48)$ & \multirow{4}{*}{0.001} & \multirow{4}{*}{ ANOVA } \\
\hline & Grade 2 & $2.52(0.98)$ & & \\
\hline & Grade 3 & $4.74(1.17)$ & & \\
\hline & Grade 4 & $4.8(0.77)$ & & \\
\hline \multirow{4}{*}{ FEV1 } & Mild & $2.09(0.65)$ & \multirow{4}{*}{0.001} & \multirow{4}{*}{ ANOVA } \\
\hline & Moderate & $2.59(1.04)$ & & \\
\hline & Severe & $4.38(1.35)$ & & \\
\hline & Very Severe & $5.01(0.84)$ & & \\
\hline \multirow{4}{*}{ Gold } & Mild & $2.03(0.47)$ & \multirow{4}{*}{0.001} & \multirow{4}{*}{ ANOVA } \\
\hline & Moderate & $2.58(1.05)$ & & \\
\hline & Severe & $4.29(1.19)$ & & \\
\hline & Very Severe & $5.08(0.86)$ & & \\
\hline \multirow{4}{*}{$\begin{array}{l}\text { 6-Min Walk } \\
\text { Distance }\end{array}$} & $>350$ MTS & $2.18(0.81)$ & \multirow{4}{*}{0.001} & \multirow{4}{*}{ ANOVA } \\
\hline & $250-349$ MTS & $3.87(1.4)$ & & \\
\hline & \begin{tabular}{|l}
$150-249$ \\
\end{tabular} & $4.19(1.28)$ & & \\
\hline & $<149$ MTS & $5.13(0.89)$ & & \\
\hline \multirow{4}{*}{$\begin{array}{c}\text { Bode Index } \\
\text { (Survival } \\
\% \text { ) }\end{array}$} & $1(80 \%)$ & $2.07(0.62)$ & \multirow{4}{*}{0.001} & \multirow{4}{*}{ ANOVA } \\
\hline & $2(67 \%)$ & 3 (1.19) & & \\
\hline & $3(57 \%)$ & 4.35 (1.44) & & \\
\hline & $4(18 \%)$ & $4.89(1.04)$ & & \\
\hline \multicolumn{5}{|c|}{$\begin{array}{l}\text { Table 4. Various Severity Grades vs. Mean Neutrophil } \\
\text { Lymphocyte Ratio }\end{array}$} \\
\hline
\end{tabular}

The biomass fuel exposure followed the same pattern of smoking as NLR was raised in those patients with exposure compared to normal population with significant $p$ value (0.005). Place of origin of patient and hypertension were not related in any form with the NLR value.

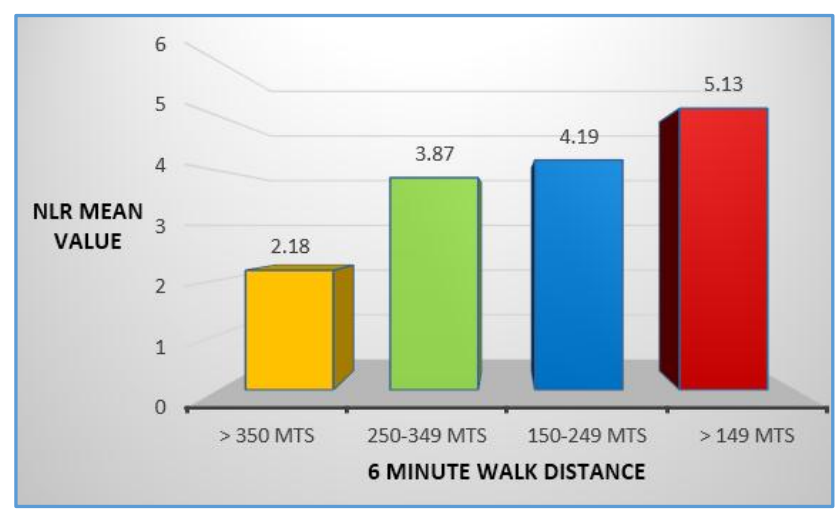

Chart 3. 6-Minute Walk Distance vs. Mean Neutrophil Lymphocyte Ratio

Fever, clubbing, cyanosis, pedal oedema, crepitation, wheezing and $\mathrm{PAH}$ showed statistical significance with $\mathrm{p}$ value of 0.001 , showing that with NLR more the severity of the disease is high. Since all the patients had cough, $p$ value for the same could not be assessed. The neutrophil lymphocyte ratio was more in patients with more severity of disease shown by MMRC grading, and it indicates that higher the NLR ratio more severe the disease will be on dyspnoea score. 


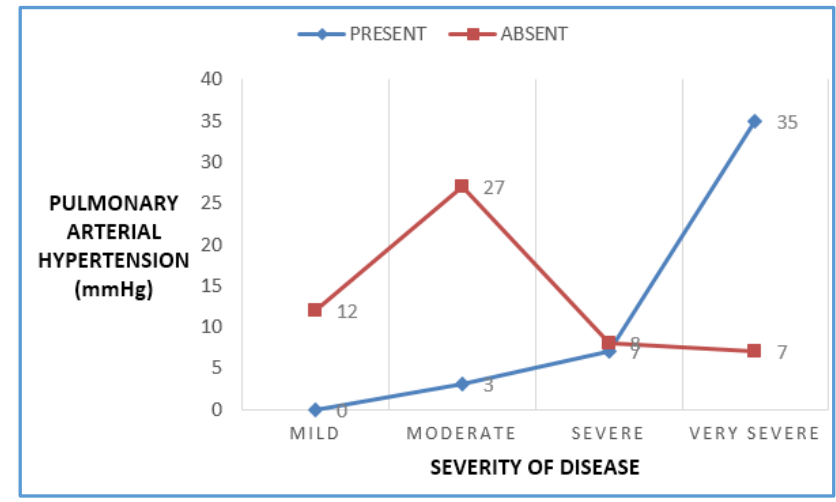

Chart 4. PAH vs. Severity of Disease

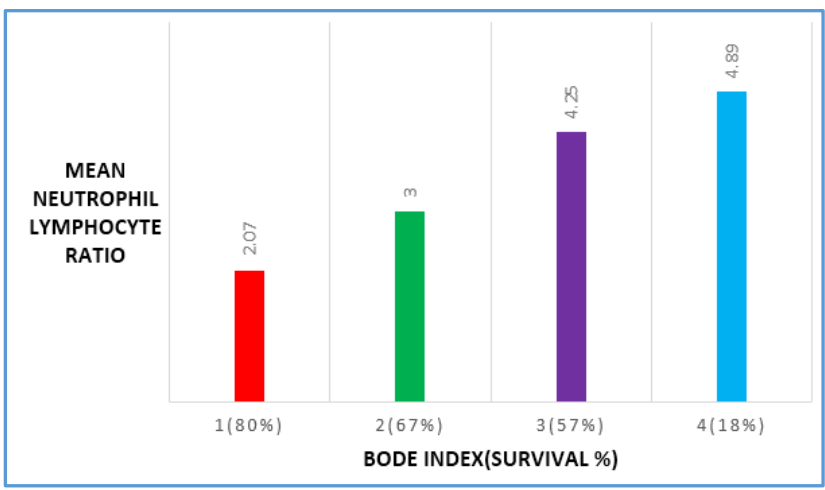

Chart 5. Bode Index vs. Mean Neutrophil Lymphocyte Ratio

Another important finding is that NLR ratio is inversely related to FEV1 and GOLD grades with p-value being 0.001, which shows the severity of obstruction in airways with more neutrophil lymphocyte ratio.

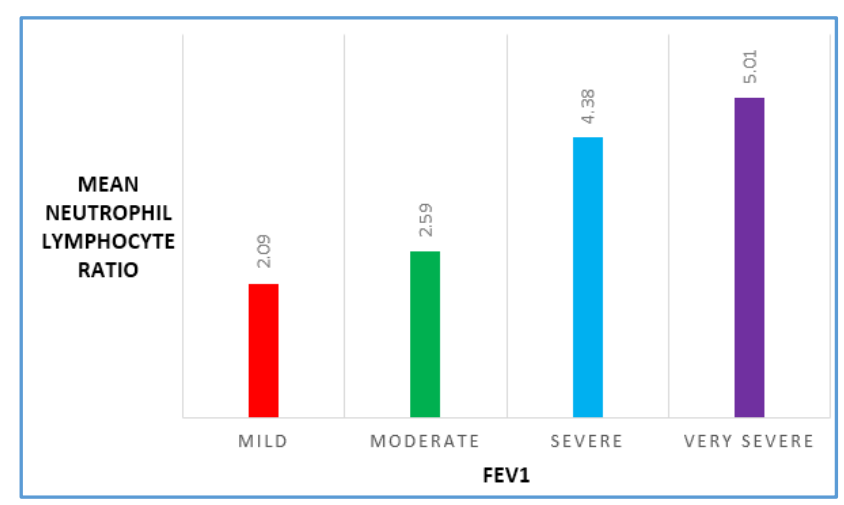

Chart 6. FEV1 vs. Mean Neutrophil Lymphocyte Ratio

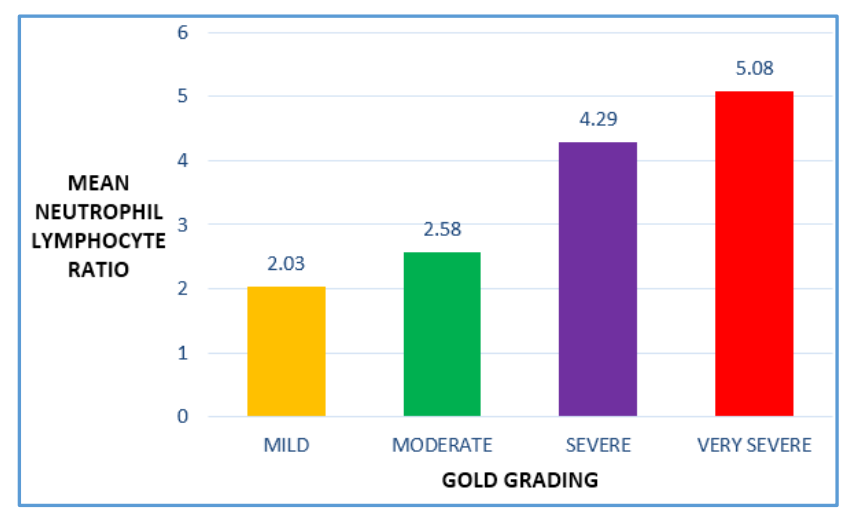

Chart 7. Gold Grading vs. Mean Neutrophil Lymphocyte Ratio
It has been found that NLR was independently correlated with all parameters of BODE index with $\mathrm{p}$ value of 0.001 . Correlation of chest x-ray and CT chest with mean NLR level for emphysema plus chronic bronchitis was 4.8 and showed statistical significance with $\mathrm{p}$ value of 0.001 .

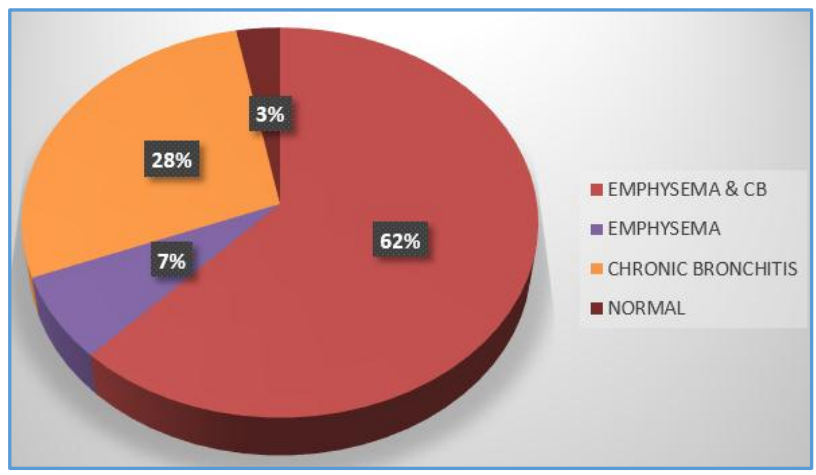

Chart 8. Chest X-Ray findings of Patients

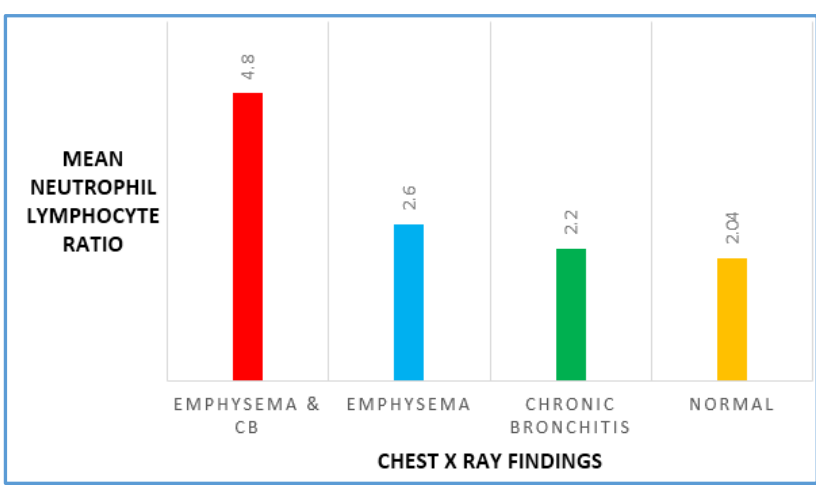

Chart 9. Chest X-Ray vs. Mean Neutrophil Lymphocyte Ratio

The NLR can be taken as a pulmonary structural and functional indicator, as it is shown that NLR is more in patients with more destruction in lung shown on $\mathrm{x}$-ray and CT scan as the possible mechanism that neutrophils degranulate causing release of enzymes and result in more emphysematous destruction.

It was also found in our study that NLR was associated with every component of the BODE index and was statistically significant with every component. So it can be said that the walking distance in 6 minutes, the nutritional status of the patient, breathlessness of the patient, everything's severity can be assessed from NLR. Another important thing is that BODE index gives the prognosis and 4year survival rate, so from the simple investigation we can predict somewhat the 4-year prognosis of the patient without costly investigations.

\section{DISCUSSION}

Chronic Obstructive Pulmonary Disease (COPD) is a preventable and treatable disease, which consists of constant expiratory limitation of the flow of air which is not fully reversible. A progressive disease, which comprises of enhanced and chronic inflammatory response to gases and noxious materials of the mucosa of respiratory tract. Though there is a complex inflammatory response within the airways and lung parenchyma during the early stages of the disease, COPD is recognised as a systemic inflammatory disease.[12] 
GOLD defines COPD- "Chronic Obstructive Pulmonary Disease (COPD) is a preventable and treatable disease that is characterised by airflow limitation and persistent respiratory symptoms that is due to airway and/ or alveolar abnormalities usually caused by significant exposure to gases or noxious particles." Factors in early life termed "childhood disadvantage factors" are as important as heavy smoking in predicting lung function in adult life.[13]

Several mechanisms have been proposed for the origin of the increased systemic inflammation of COPD. First, the spill over of inflammatory mediators from the pulmonary compartment; Second, an inflammatory reaction to tissue hypoxia; and Third a reaction induced by the proinflammatory bacterial product lipopolysaccharide. [14]

The neutrophil-to-lymphocyte ratio (NLR) is a simple ratio that is obtained from the complete blood count of patient, which is found out by dividing absolute neutrophil count as numerator and absolute lymphocyte count as the denominator. So any conditions which alters the counts will change the ratio, which can increase or decrease. The ratio indicates the inflammatory status of the individual, that is the cellular mediated inflammatory response. High value of the ratio indicates there is some response to inflammation happening in the body. In connection with WBC count and its subtypes, several studies have shown the prognostic value of leucocytosis and neutrophilia in the systemic circulation in patients with COPD. An elevated WBC count was also associated with increased risk of frequent exacerbations. ${ }^{[15,16]}$ Celli et al showed that elevated WBC and neutrophil counts were independently and significantly associated with mortality.[17]

In Danish COPD population study, leucocytosis in combination with elevated levels of CRP and fibrinogen was associated with an increased risk of major comorbidities such as ischaemic heart disease, diabetes, lung cancer and pneumonia.[18] So many of the conditions NLR can vary and its value can be used in monitoring as a biomarker in those conditions, some are hypertension, diabetes, obesity, metabolic syndromes, cardiovascular disease, renal failure, any chronic malnutrition states, cerebrovascular disease, Alzheimer's, COPD and even psychiatric conditions like delirium etc. This parameter can also be used in various cancers, monitoring of therapy of drugs and prognosis of treatment with various therapies. The usefulness of NLR as an inflammatory marker can compared to other routinely used inflammatory markers like C-reactive protein interleukin-1, tumour necrosis factor- $\alpha$, ESR etc. Neutrophil was considered to be the culprit of a protease/ antiprotease imbalance in the lung. Neutrophils attached to endothelial cells and migrate into the respiratory tract through the airways and parenchyma with the help of neutrophil chemotactic factors and then lastly survive by some cytokines.[19]

Cigarette smoking is considered as one of the important reasons which results in COPD according to WHO, the smoke originating from the cigarette consists of many different free radicals along with other oxidant substances. These will cause inflammation in the lining epitheliums of airway tracts and also in the parenchyma of the lung tissue along with surplus production of mucus decreases the airflow to lungs resulting in COPDs pathological and clinical features. Smoking will reduce the flow rates and decreases the pulmonary function.

Smoking cessation is the most important and the effective treatment of COPD. It decreases the rapidity of development of pulmonary deterioration. Recently, Milara et al reported that the peripheral blood neutrophil count was persistently elevated in patients with COPD despite years of smoking cessation.[20] Cigarette smokers have a higher prevalence of respiratory symptoms and lung function abnormalities, a greater annual rate of decline in FEV1 and a greater COPD mortality rate than non-smokers. ${ }^{[21]}$

Passive exposure to cigarette smoke also known as environmental tobacco smoke, may also contribute to respiratory symptoms and COPD ${ }^{[22]}$ by increasing the lung's total burden of inhaled particles and gases. Pregnant women who smokes had greater risk for the foetus by affecting in utero lung growth and development and possibly priming the immune system.[23] Occupational exposures including organic and inorganic dusts, chemical agents and fumes are underappreciated risk factors for COPD development.[24,25]

\section{Protease-Antiprotease Hypothesis}

Alpha-1-antitrypsin ( $\alpha 1-\mathrm{AT})$, also called $\alpha$-1-protease inhibitor $(\alpha-1-\mathrm{Pi})$, is a glycoprotein that forms the normal constituent in the $\alpha$-1-globulin part of the plasma proteins on serum electrophoresis. The single gene locus that codes for $\alpha$ -1-AT is whose locus is on chromosome $15^{\text {th }}$ long arm. The normal function of $\alpha-1-\mathrm{AT}$ is to inhibit proteases and hence its name $\alpha-1$-protease inhibitor. The proteases (mainly elastases) are derived from neutrophils. Neutrophil elastase normally in lung tissue is prevented from eating the lung parenchyma, because of the anti-elastase activity of the enzyme. So, any alterations in the system can result in the pathology occurring in emphysema- By decreased antielastase activity, i.e. deficiency of $\alpha-1$ antitrypsin; By increased activity of elastase, i.e. increased neutrophilic activation and also lung infiltration producing more neutrophil elastase.

Recently, it has been found that the use of NLR in various cancer prognostication including breast cancer, oesophageal cancer, pancreatic cancer, colorectal cancers, an elevated preoperative or pretreatment NLR calculated from peripheral blood tests was identified as an independent and readily available prognostic biomarker related to poor survival in numerous cancers including colorectal cancer, breast cancer, gastric cancer and oesophageal cancer, renal cell carcinomas and various studies are undergoing in evaluating the same as inflammation is a basic pathogenesis happening in all cancers and in those states the NLR values are altered.

NLR is a tool which helps to find out the severity of disease and also the activity status of the disease in COPD patients. Similar study, Lee et al found that neither neutrophil nor lymphocyte alone was correlated with FEV1. The Neutrophil Lymphocyte Ratio was very well correlated with FEV1. Neutrophilia, an indicator of inflammation, and lymphopenia, an indicator of decreased immune competence, predicts the severity and activity of COPD while combining both as an NLR rather than neutrophilia or lymphopenia alone.[26] 


\section{Significance of NLR}

1. NLR levels are related to FEV1 by inverse relationship, as NLR increases FEV1 decreases.

2. COPD exacerbations can be predicted with NLR and if NLR is more in routinely followed patients we can say the chances of future exacerbations are more.

3. The severity of the exacerbation state can be said by the NLR value without the help of spirometry.

4. NLR can also predict the prognosis of the COPD patient by comparing it with the BODE index.

In COPD, there will be continuous inflammatory process happening in the airways and also in the lung tissues. Nowadays, COPD is thought to be a systemic inflammatory disease, as a result of that the levels of inflammatory markers which are in blood will be high compared to normal subjects. It has been found out that even in normal states in COPD patients the inflammatory marker levels will be higher than in healthy subjects, and higher the markers higher the chances that patients can get future exacerbations. The extent of airflow obstruction and inflammation in small airways are associated with COPD severity as reflected in the GOLD stages.[27,28,29]

It has been well accepted for the elevation of WBC and neutrophils in COPD. COPD patients who had increased inflammatory markers like CRP, fibrinogen with increased WBC count has greater chances of getting comorbid conditions like pneumonia, diabetes, lung cancer, CAHD etc. Those who have frequent exacerbations have elevated WBC counts in their blood picture and their raised value is a predictor of mortality. Elevated WBC and neutrophil counts were independently and significantly associated with mortality. On the other hand, several studies found that the increase in lymphocytes has been suggested to be caused by chronic immune stimulation due to infectious pathogens. Although, the impact of lymphopenia on chronic inflammatory disease has not been well known, lymphopenia was associated with poor outcomes in patients with an acute infectious disease such as sepsis or bacteraemia.[30]

In addition, lymphopenia was found to be related to allcause mortality in patients with COPD.[31,32] So there comes the role of NLR, which consists of both the things in which increased neutrophil count indicates activity of inflammation and decreased lymphocyte count shows poor general condition and the incompetence of immune system. Lymphopenia is associated with poor outcomes in patients with acute medical conditions such as sepsis, bacteraemia and trauma and also in patients with chronic diseases such as cardiovascular diseases, cancers and inflammatory bowel disease. The mechanism of lymphopenia in critically ill patients involve apoptosis and redistribution of lymphocytes, but little is known about the causes of lymphopenia in patients with chronic inflammatory diseases. Lymphopenia is associated with age and poor nutritional status which also characterises COPD. [33]

Neutrophilia an indicator of inflammation and lymphopenia an indicator of decreased immune competence, predicts the severity and activity of COPD while combining both as an NLR rather than neutrophilia or lymphopenia alone. The underlying mechanism between the NLR value and airflow obstruction/ exacerbation is not well understood. Several studies have shown that neutrophils are a key mediator of the relentless decline in lung function in patients with COPD. After the recruitment, activated neutrophils cause tissue destruction in lungs by releasing oxygen radicals and proteolytic enzymes such as neutrophil elastase and matrix metalloproteinases, which ultimately results in alveolar destruction and emphysema. Emphysematous change may lead to chronic airway obstruction by affecting the structure and contractility of airway smooth muscle when neutrophils are combined with small airway disease. When activated, neutrophils release a number of proteolytic enzymes such as elastase and matrix metalloproteinase, which contributed to the development of emphysema. Increased neutrophil count in airway correlated with the rate of decline in the lung function.

While combining both the factors, NLR and the FEV1 helps to assess further exacerbations of COPD and also the rise in NLR values showed decreased exercise capacity of the patient. So everything adds to the fact that NLR reflects the severity and helps to monitor the same.

The mechanism of what happens in acute exacerbations explain the relationship of NLR and disease severity as increased neutrophils in lung will cause the release of many of proteolytic enzymes from its granules like elastase matrix metalloproteinases which are considered as culprits in emphysema. So it can be found that airway neutrophilia is inversely related to the lung function. Our study depicts NLR value to FEV1 accurately predicts further disease exacerbations. With the patient's symptoms, as the NLR value increases and exercise capacity worsens. To conclude, the NLR may be used as simple peripheral blood marker to reflect the severity and activity of COPD.

\section{CONCLUSION}

In various stressful events, physiological response of circulating leucocytes is characterised by an increase in neutrophil counts and a decline in lymphocyte counts. Neutrophilia is caused by demargination of neutrophils, delayed apoptosis of neutrophils and stimulation of stem cells by growth factors. Margination of lymphocytes, redistribution of lymphocytes and marked accelerated apoptosis are the supposed mechanisms of observed lymphocytopenia in infectious emergencies.[34] Lymphocytopenia has shown promising results in the prediction of bacteraemia in infectious emergency admissions.[35]

Recently, NLR has been "re-discovered" as a simple and promising marker in several clinical circumstances.[36,37] The NLR had a significant inverse relationship to FEV1 and will be a prognostic indicator for further exacerbations in patients with stable COPD. In our study, NLR was independently correlated with all parameters of BODE index. So, it can be said that the walking distance of 6 minutes, the nutritional status of the patient, breathlessness of the patient, every severity can be assessed from NLR. Another important thing is that BODE index gives the prognosis and 4-year survival rate. So, from the simple investigation we can predict to certain extent, the 4-year prognosis of a patient without getting expensive investigations done. Those who had greater ratio of NLR usually had more severe the disease. The prognosis and survival rate will be poor in high NLR ratio patients and these patients can be picked up early with NLR 
and have to be effectively intervened and rehabilitated to decrease the mortality and morbidity so that they can have good quality of life.

\section{ACKNOWLEDGEMENTS}

We are extremely grateful to Dr. S. Keerthivasan, MD (Pulmonology), for his valuable help and cooperation.

\section{REFERENCES}

[1] Mannino DM, Buist AS. Global burden of COPD: risk factors, prevalence, and future trends. Lancet 2007;370(9589):765-73.

[2] MacNee W. Pathogenesis of chronic obstructive pulmonary disease. Proc Am Thorac Soc 2005;2(4):258-66.

[3] Han YC, Yang TH, Kim DI, et al. Neutrophil to lymphocyte ratio predicts long-term clinical outcomes in patients with ST-segment elevation myocardial infarction undergoing primary percutaneous coronary intervention. Korean Circ J 2013;43(2):93-9.

[4] Templeton AJ, McNamara MG, Šeruga B, et al. Prognostic role of neutrophil-to-lymphocyte ratio in solid tumors: a systematic review and meta-analysis. J Natl Cancer Inst 2014;106(6):dju124.

[5] Yoon NB, Son C, Um SJ. Role of the neutrophillymphocyte count ratio in the differential diagnosis between pulmonary tuberculosis and bacterial community-acquired pneumonia. Ann Lab Med 2013;33(2):105-10.

[6] Bousquet J, Khaltaev N. Global surveillance, prevention and control of chronic respiratory diseases. A comprehensive approach. Geneva, Switzerland: World Health Organization 2007.

[7] WHO. World health statistics 2008. Geneva: World Health Organization 2008.

[8] McKay AJ, Mahesh PA, Fordham JZ, et al. Prevalence of COPD in India: a systematic review. Prim Care Respir J 2012;21(3):313-21.

[9] Lopez AD, Shibuya K, Rao C, et al. Chronic obstructive pulmonary disease: current burden and future projections. Eur Resp J 2006;27(2):397-412.

[10] Jindal SK, Aggarwal AN, Gupta D. A review of the population studies from India to estimate national burden of chronic obstructive pulmonary disease and its association with smoking. Indian J Chest Dis Allied Sci 2001;43(3):139-47.

[11] Jindal SK, Aggarwal AN, Gupta D, et al. Indian study on epidemiology of asthma, respiratory symptoms and chronic bronchitis in adults (INSEARCH). Int J Tuberc Lung Dis 2012;16(9):1270-7.

[12] Walter RE, Wilk JB, Larson MG, et al. Systemic inflammation and COPD: the Framingham Heart Study. Chest 2008;133(1):19-25.

[13] Furutate R, Ishii T, Motegi T, et al. The neutrophil to lymphocyte ratio is related to disease severity and exacerbation in patients with chronic obstructive pulmonary disease. Intern Med 2016;55(3):223-9.

[14] Thomsen $M$, Ingebrigtsen TS, Marott JL, et al. Inflammatory biomarkers and exacerbations in chronic obstructive pulmonary disease. JAMA 2013;309(22):2353-61.
[15] Bathoorn E, Kerstjens H, Postma D, et al. Airways inflammation and treatment during acute exacerbations of COPD. Int J Chron Obstruct Pulmon Dis 2008;3(2):217-29.

[16] Hurst JR, Vestbo J, Anzueto A, et al. Susceptibility to exacerbation in chronic obstructive pulmonary disease. N Engl J Med 2010;363(12):1128-38.

[17] Celli BR, Locantore N, Yates J, et al. Inflammatory biomarkers improve clinical prediction of mortality in chronic obstructive pulmonary disease. Am J Respir Crit Care Med 2012;185(10):1065-72.

[18] Thomsen $M$, Dahl $M$, Lange $P$, et al. Inflammatory biomarkers and comorbidities in chronic obstructive pulmonary disease. Am J Respir Crit Care Med 2012;186(10):982-8.

[19] Rovina N, Koutsoukou A, Koulouris NG. Inflammation and immune response in COPD: where do we stand? Mediators Inflamm 2013;2013:413735.

[20] Milara J, Juan G, Peiro T, et al. Neutrophil activation in severe, early-onset COPD patients versus healthy nonsmoker subjects in vitro: effects of antioxidant therapy. Respiration 2012;83(2):147-58.

[21] Hogg JC, Chu F, Utokaparch S, et al. The nature of small-airway obstruction in chronic obstructive pulmonary disease. N Engl J Med 2004;350(26):264553.

[22] Yin P, Jiang CQ, Cheng KK, et al. Passive smoking exposure and risk of COPD among adults in China: the Guangzhou Biobank Cohort Study. Lancet 2007;370(9589):751-7.

[23] Tager IB, Ngo L, Hanrahan JP. Maternal smoking during pregnancy: effects on lung function during the first 18 months of life. Am J Respir Crit Care Med 1995;152(3):977-83.

[24] Paulin LM, Diette GB, Blanc PD, et al. Occupational exposures are associated with worse morbidity in patients with chronic obstructive pulmonary disease. Am J Respir Crit Care Med 2015;191(5):557-65.

[25] Eisner MD, Anthonisen N, Coultas D, et al. An official American Thoracic Society public policy statement: novel risk factors and the global burden of chronic obstructive pulmonary disease. Am J Respir Crit Care Med 2010;182(5):693-718.

[26] Lee H, Um SJ, Kim YS, et al. Association of the neutrophil-to-lymphocyte ratio with lung function and exacerbations in patients with chronic obstructive pulmonary disease. PLoS One 2016;11(6):e0156511.

[27] Furutate R, Ishii T, Motegi T, et al. The neutrophil to lymphocyte ratio is related to disease severity and exacerbation in patients with chronic obstructive pulmonary disease. Intern Med 2016;55(3):223-9.

[28] Hogg JC, Chu F, Utokaparch S, et al. The nature of small-airway obstruction in chronic obstructive pulmonary disease. N Engl J Med 2004;350(26):264553.

[29] Retamales I, Elliott WM, Meshi B, et al. Amplification of inflammation in emphysema and its association with latent adenoviral infection. Am J Respir Crit Care Med 2001;164(3):469-73.

[30] Drewry AM, Samra N, Skrupky LP, et al. Persistent lymphopenia after diagnosis of sepsis predicts mortality. Shock 2015;42(5):383-91. 
[31] Sørensen AK, Holmgaard DB, Mygind LH, et al. Neutrophil-to-lymphocyte ratio, calprotectin and YKL40 in patients with chronic obstructive pulmonary disease: correlations and 5-year mortality-a cohort study. J Inflamm 2015;12:20.

[32] Gunay E, Sarinc Ulasli S, Akar O, et al. Neutrophil-tolymphocyte ratio in chronic obstructive pulmonary disease: a retrospective study. Inflammation 2014;37(2):374-80.

[33] Landbo C, Prescott E, Lange P, et al. Prognostic value of nutritional status in chronic obstructive pulmonary disease. Am J Respir Crit Care Med 1999;160(6):185661.

[34] Unsinger J, Kazama H, McDonough JS, et al. Differential lymphopenia-induced homeostatic proliferation for CD4+ and CD8+ $\mathrm{T}$ cells following septic injury. J Leukoc Biol 2009;85(3):382-90.
[35] Wyllie DH, Bowler IC, Peto TE. Bacteraemia prediction in emergency medical admissions: role of $\mathrm{C}$ reactive protein. J Clin Pathol 2005;58(4):352-6.

[36] Gibson PH, Croal BL, Cuthbertson BH, et al. Preoperative neutrophil-lymphocyte ratio and outcome from coronary artery bypass grafting. Am Heart J 2007;154(5):995-1002.

[37] Sarraf KM, Belcher E, Raevsky E, et al. Neutrophil/lymphocyte ratio and its association with survival after complete resection in non-small cell lung cancer. J Thorac Cardiovasc Surg 2009;137(2):425-8. 